\title{
Closed Cycle Drying Process To Retrain Industrial Sludge into Construction Products
}

\author{
Antonino D'Urso ${ }^{\#}$, Vito Cutraro ${ }^{\#}$, Carla Catania ${ }^{\#}$, Filippo Rapisarda ${ }^{\#}$, Giovanni Garaffo ${ }^{*} \&$ Michele Calì ${ }^{+}$ \\ \# 4R Ecologia \& Costruzioni S.r.l., V.le Santuario Maria SS. Gulfi, 5/C, 97012 Chiaramonte Gulfi (RG), Italy. \\ *Progetto PON I\&C Horizon 2020 TAFIPACC, Italy \\ ${ }^{+}$Department of Electric, Electronics and Computer Engineering, University of Catania, V.le A. Doria, 6, 95125 Catania Italy. \\ E-mail:michele.cali@dieei.unict.it
}

\begin{abstract}
The article describes a new bio-inspired method for the Advanced Treatment of Industrial Sludge with a Closed Cycle Drying Process. This process represents an innovative way of treating sludge and other shovelable residues deriving from sludge treatment with centrifuges and other industrial processes taking place in large installations, such as refineries, steel mills, chemical plants, glass processing installations, cosmetics manufacturing facilities, pharmaceutical plants. The process is under development within the research project TAFIPACC funded by Horizon 2020. In particular, the process allows retraining Industrial Sludge into construction materials using the new Closed Cycle Drying Process. The study deals with sludge produced by an industrial treatment plant/industrial discharges and civil waste water in the industrial area of Priolo Gargallo (SR) Esso-Erg-Enichem petrochemical plants and by the municipalities of Priolo Gargallo, and Melilli. The plants produce about 30 cubic meters of sludge per day, disposed of $50 \%$ in underground dumps and for the other $50 \%$ in hazardous and non hazardous waste recovery plants. The difficulty in the treatment is mainly due to the nature of these muds, as pasty and difficult to mix with additives (cement, limestone, H2O, granulometric mix). The presence of bad odours derives from light and heavy hydrocarbons, aromatics, and organic solvents (benzene, toluene, styrene, xylene, etc), causing some problems to operators and inhabitants living in the areas surrounding the plants.
\end{abstract}

Keywords — sludge treatment; process design; recycling; bio-inspired; de-pollution.

\section{INTRODUCTION}

The muddy slurry has for a large part an organic nature and comes from a treatment with centrifuge that removes about $35-40 \%$ of the humidity making it shovelable at the end of the process. The hazardous sludge with CER 190813* being object of the proposed treatment is transported to the treatment plant with a watertight sealed dump truck [1]-[3].

Once in plant, the sludge is discharged and confined in bays on an approximately 15,000 meters area, from there transported into an inerting system plant and mixed with various additives (quality limestone, granulometric mix, lime, cement, $\mathrm{H}_{2} \mathrm{O}$, substances for odour abatement) [4].

The primary-secondary material "MPS" produced derived from the treatment is submitted to solidification in different caissons and after that removed and deposited in storage areas, whilst awaiting the residues transport testing "Attachment 3 of DM 186/2006" that validate the possibility of their re-use in the building and construction industry [5]-[6].
The procedure implemented in the $4 \mathrm{R}$ Ecologia \& Costruzioni Srl plant is one the few procedures in Italy treating the recovery of products from hazardous waste recycling, stabilized to be reused in various sectors (retaining walls, road foundations, fills, buildings, etc.) so as to avoid sending them to the waste disposal site, which will not permit any type of recovery.

This research (developed within TAFIPACC Project) proposes to "drain" the mud with a pilot plant, as a result of the research and experimentation on $1,000 \mathrm{~kg} / \mathrm{day}$, performing this function by using electricity or steam in order to accelerate the drying process, thus permitting a substantial mud volume abatement of about $1 / 3$ and a reduction of bad smells.

The research team has used muddy creek wastewater, defined as hazardous by the current regulation being in use in Italy and Europe. The chemical/physical analyses have shown the presence of different kind of heavy metals and hydrocarbons, thus it was possible to classify waste as hazardous. 


\section{MATERIALS AND METHODS}

The TAFIPACC project aims to develop a new methodology for the treatment of hazardous and nonhazardous sludge, putting at the center of the whole plant a 3 mc planetary mixer that is also flanked by a series of devices that allow the extraction of the volatile and polluting part of the processed waste.

The planetary mixer will have the innovative feature to allow the insertion of cement, lime, additives and water in the central part of the tank. This characteristic, for machines of these capacities, is not yet available on the world market since the central part of the machine is usually occupied by the transmission components.

The benefit of this innovation results in a better mixing process of the ingredients which is faster and of better quality (they avoid unevenness). In fact, the ingredients loaded at the centre due to the significant centrifugal force tend to move towards the external perimeter of the mixer, favouring the homogenization of the different components within the entire mixer.

The mud is moved by mechanical shovels and loaded into a tube that leads into a depressurized container, where a mechanical propeller moves all the time long. The treatment plant is composed of a "dehumidifier", fed by a $180^{\circ}$ boiler and the mud is kept inside for 3 hours at least.

During the drainage phase, the liquid part is conveyed in a $5 \mathrm{mc}$ hermetic silo so as to contain the odors coming from the hydrocarbons that are still in the mud.

Outside the plant and during the drainage phase, once the doors are closed over a hopper, no smells or noised can be heard.

After about a 3 hour drainage, the drain under the "dehumidifier" is opened, the drained mud is in the form of dust and without moisture.

The "dehumidifier" has allowed to remove $1 / 3$ of the moisture contained in the mud, to be positioned then in a "conveyor belt" and finally inside a silo. In figure 1 the process diagram is shown.

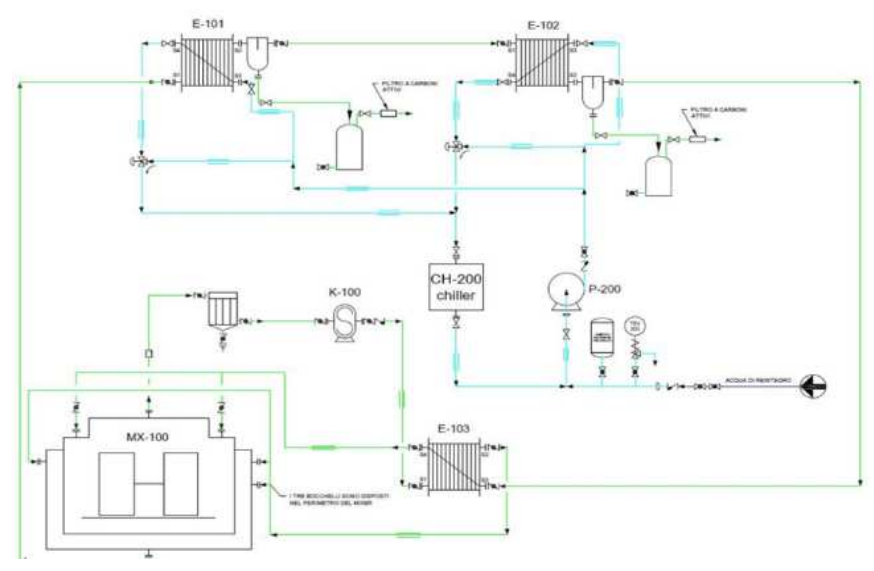

Fig. 1 Process diagram.

In the dehydration process the plant consists of a planetary mixer equipped with a shirt to circulate the hot fluid from the process to recover part of the heat supplied to the plant. The vapours which are released from the mixer, consisting of water and volatile substances, are sucked in by the K-compressor100 through a heat recovery exchanger system that serves to condense condensing components while non-condensing components will be sent to the next step.

The compressor keeps the vacuum inside the mixer at 0.8 bar to improve the evaporation of the components.

The compression of vapours causes a rise in temperature and therefore energy that will be partly used to heat the incoming current to the mixer via the E-exchanger103, and subsequently will be recovered in the shirt of the mixer to heat the charge input to the plant.

The gaseous current coming out of the cooled sleeve is ready to be dehumidified in the first stage through the E-101 exchanger which lowers the temperature to $20^{\circ} \mathrm{C}$ through a refrigerated water circuit.

In this phase the first condensation and separation of the flue gas from the liquid effluent is achieved, the volume of which is a function of the moisture content of the incoming current.

The gaseous current outgoing from E-101 will undergo a further cooling to $5^{\circ} \mathrm{C}$ in a second exchanger E-102 that also in this case will separate the condensable.

Two-stage condensation allows the condensate to be fractionated in order to differentiate the methods of disposal and possibly re-inject them into the processing cycle (this possibility must be confirmed during the tests).

Downstream of each exchanger, at the head of the condensate collection barrel, is inserted a venting filtered with activated carbon that will open only if the pressure inside the system exceeds a preset threshold.

The dehumidified vapours will be fed back into the planetary mixer after heating through the E-103 exchanger mentioned above. The cold carrier fluid is generated by a chiller that will be dedicated to removing heat from the exchangers.

Future developments could adopt other types of heating energy, such as hot water from methane boilers, or hot water from other production processes or solar panels or use a biomass boiler that would heat diathermic oil producing heat at about a temperature of $130^{\circ} \mathrm{C}$ inside the mixer. At the moment temperature is relatively low $\left(40^{\circ}-50^{\circ}\right)$ thus causing a deficit during the stage of dehydration. The mixer will also be equipped with a humidity sensing probe which, by sending the data to the automation supervisor device, allow constant monitoring of the drying process and automatic maintenance of certain residual moisture values.

The machine will be dimensioned to treat a high hourly quantity of 1 ton/h of polluted mud and to produce consequently 3 cubic meters/h of concrete made vibrated of high quality and suitable therefore to be used (through special equipment already available on the market) for the packaging of products of different kinds and of high quality (tiles, building blocks, paving, heavy blocks for various uses, etc.).

This results in an additional added value of the sludge treatment process with the profitable reuse of the output material (MPS). Approximately 1 ton of sludge will be treated: 1.7 ton of clean inert and 0.6 ton of cement and if necessary lime in pre-established doses based on the type of incoming waste. 
These are initial reference values that need to be checked and optimized during the search. 3 ton of sludge is intended to extract $30 \%$ of the liquid from the sludge with the circulation of the air in the distillers. The objective of this liquid part is to obtain $50 \%$ clean and immediately usable water and $50 \%$ will be disposed of in the centres authorized for their treatment. In the trial phase, both components, clean and otherwise, will first be analysed and then sent to an approved disposal facility.

\section{A. Sludge drainage treatment}

The drained sludge is transferred to a silo armed with an internal rotating agitator or mixer (Fig. 2), where most of the additives necessary for the treatment of aggregates (limestone and cement) are introduced and therefore the continuous mixing allows the sludge to lose some of the characteristics proper to its condition, such as odor and water absorption, which is not easy considering the presence of hydrocarbons [7]-[10].

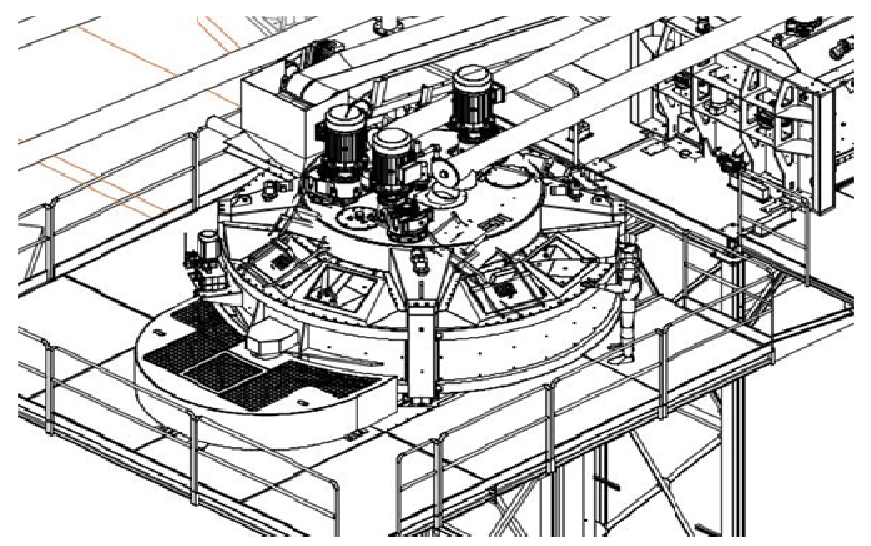

Fig. 2 New Mixer in TAFIPACC project.

In the works [11]-[14] it is possible to find major information regarding the TAFIPACC project and the new process developed, while in the works [15]-[21] the descriptions of the methods used, the results obtained and some of the solutions adopted in the design of the new TAFIPACC method are reported. In figure 3 a scaled prototype of the treatment implant and the complete system installed at the 4R Company in Chiaramonte Gulfi are shown.

\section{B. The purification treatment}

The dried mud is mixed in silo with an additive process and a few hours later the treatment plant that mixes water and mixed grains starts. The water used for the dough comes from a "dehumidifier" that has been connected to the silo of about 30 cubic meters and after 30 minutes it is discharged into metal frames of various sizes ( $\mathrm{m} 3 \times 2 \times 1,1 \times 1 \times 1)$ and left to mature for a few days.

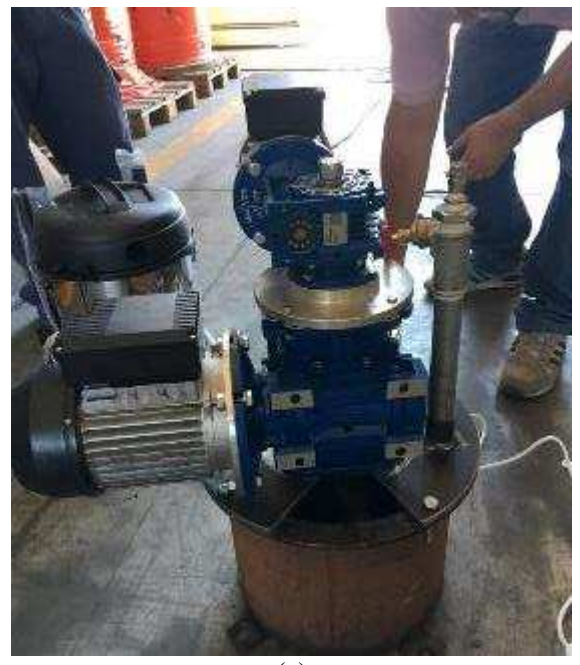

(a)

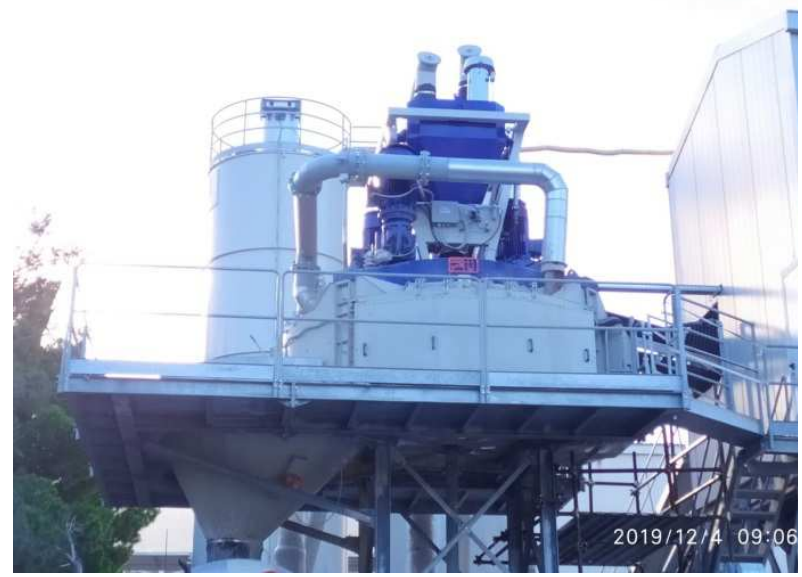

(b)

Fig. 3 TAFIPACC Implant: (a) scaled prototype; (b) complete system.

\section{Immersion treatment in limestone or other anti- odorogenic liquid additives}

After hardening, the blocks are transferred to the storage area, where the frames are removed and some sampled are taken to be sent to the laboratory caring out tests. Testing results will be able to certificate that the artifact is a secondary raw material (mps) and no longer a waste and classified as a commercial product to be reused in different sectors (construction, environmental restoration, road bases, etc.).

One of the traditional techniques currently used for the inertization of hazardous (and non-hazardous) sludge is to package concrete with it. In this way the pollutants present in the sludge are incorporated in the cement matrix with high resistance. If we had to simulate a possible scenario in case of application of the TAFIPACC method and its possible benefits (Tab. 1). 
TABLE I

PRINCIPAL BENEFITS OF THE TAFIPACC METHOD

\begin{tabular}{|l|c|c|c|}
\hline \multicolumn{1}{|c|}{$\begin{array}{c}\text { Component } \\
\text { Description }\end{array}$} & $\begin{array}{c}\text { Initial } \\
\text { Formula } \\
{[\mathbf{K g}]}\end{array}$ & $\begin{array}{c}\text { Formula After } \\
\text { Treatment } \\
{[\mathbf{K g}]}\end{array}$ & $\begin{array}{c}\text { DELTA } \\
{[\mathbf{K g}]}\end{array}$ \\
\hline $\begin{array}{l}\text { Sludge's Dried } \\
\text { Part }\end{array}$ & 426 & 426 & 0 \\
\hline $\begin{array}{l}\text { Water (In the } \\
\text { dried Sludge) }\end{array}$ & 574 & 426 & -150 \\
\hline Cement & 1435 & 1060 & -375 \\
\hline Clean Inert & 5113 & 3666 & -1447 \\
\hline Lime & 1200 & 709 & -491 \\
\hline Concrete & 8748 & 6825 & -2463 \\
\hline
\end{tabular}

\section{RESULTS AND DISCUSSION}

The cost of waste contribution to the reception facilities would amount to 174 Euros per ton Considered that the transport incidence is $12.5 € /$ ton, treatment costs per ton of sludge results in $1081700 / 5800=186.5 € /$ ton; minus the shipping costs $1865.5-12.5=174 € /$ ton, so 145 the price for the treatment of 1 ton of sludge is $174 € /$ ton). We can compare the economic results of the different methods, considering the costs of valuable materials and learning that the selling price of 1 cubic meter concrete is $35 €$ (Tab. 2), (Tab. 3), (Tab. 4).

TABLE II

PRINCIPAL BENEFITS OF THE TRADITIONAL METHOD.

\begin{tabular}{|l|c|c|c|c|c|}
\hline $\begin{array}{c}\text { Component } \\
\text { Description }\end{array}$ & $\begin{array}{c}\text { Weigth } \\
{[\mathbf{k g}]}\end{array}$ & $\begin{array}{c}\text { Volume } \\
{[\mathbf{I t}]}\end{array}$ & $\begin{array}{c}\text { Weigth } \\
{[\mathbf{K g} / \mathbf{m c} \text { of }} \\
\text { conc.] }\end{array}$ & $\begin{array}{c}\text { Cost } \\
{[\text { euro/t] }}\end{array}$ & $\begin{array}{c}\text { Total } \\
\text { Cost } \\
{[\text { euro] }}\end{array}$ \\
\hline $\begin{array}{l}\text { Sludge's Dried } \\
\text { Part }\end{array}$ & 426 & 266.25 & 112.546 & -174 & -174 \\
\hline $\begin{array}{l}\text { Water (In the } \\
\text { dried Sludge) }\end{array}$ & 574 & 574 & 151.646 & -174 & \\
\hline Cement & 1435 & 478.33 & 379.116 & 70 & 100.45 \\
\hline Clean Inert & 5113 & 1966.53 & 1350.82 & 5 & 25.565 \\
\hline Lime & 1200 & 500 & 317.031 & 107 & 128.4 \\
\hline Concrete & 8748 & 37845 & 2311 & & 80.415 \\
\hline
\end{tabular}

TABLE III

PRINCIPAL BENEFITS OF THE TAFIPACC METHOD.

\begin{tabular}{|l|c|c|c|c|c|}
\hline $\begin{array}{c}\text { Component } \\
\text { Description }\end{array}$ & $\begin{array}{c}\text { Weigth } \\
{[\mathbf{k g}]}\end{array}$ & $\begin{array}{c}\text { Volume } \\
{[\mathbf{I t}]}\end{array}$ & $\begin{array}{c}\text { Weigth } \\
{[\mathbf{K g} / \mathbf{m c} \text { of }} \\
\text { conc.] }\end{array}$ & $\begin{array}{c}\text { Cost } \\
{[\text { euro/t] }}\end{array}$ & $\begin{array}{c}\text { Total } \\
\text { Cost } \\
{[\text { euro] }}\end{array}$ \\
\hline $\begin{array}{l}\text { Sludge's } \\
\text { Dried Part }\end{array}$ & 426 & 2665 & 154 & -174 & -174 \\
\hline $\begin{array}{l}\text { Water (In the } \\
\text { dried Sludge) }\end{array}$ & 424 & 424 & 154 & -174 & \\
\hline Cement & 1060 & 353 & 385 & 70 & 74.2 \\
\hline Clean Inert & 3665 & 1409 & 1333 & 5 & 18.32 \\
\hline Lime & 709 & 295 & 257 & 107 & 75.87 \\
\hline Concrete & 6285 & 2748 & 2286 & & -5.59 \\
\hline
\end{tabular}

TABLE IV

PRINCIPAL BENEFITS OF THE TAFIPACC METHOD.

\begin{tabular}{|l|c|c|}
\hline & TRADITIONAL & TAFIPACC \\
\hline $\begin{array}{l}\text { Cost of raw Material } \\
\text { [Euro] }\end{array}$ & -80 & 5.6 \\
\hline Sale revenue [Euro] & 132.3 & 97.3 \\
\hline Margin [Euro] & 52.3 & 66.9 \\
\hline $\begin{array}{l}\text { Margin increase for a } \\
\text { tone of sudge }\end{array}$ & \multicolumn{2}{|c|}{14.6 euro } \\
\hline
\end{tabular}

The treatment of industrial muddy liquids defined as hazardous on the basis of the chemical/physical analyses is conferred in treatment plant for aqueous waste solutions with CER 16.10.02.

The dehumidified sludge has lost some of its characteristics (odor, consistency, humidity) and has changed into a dusty form that makes easier both treatment and storage.

The dehumidification treatment to be expected in the near future is presented as the sludge volume reduction of $2 / 3$ would reduce in this way the costs of daily transport operations to the treatment plant (nowadays 30 ton/day in about $100 \mathrm{~km}$ ) while the drained sludge will decrease the number of trips to 3 per week intended inserted in silo.

This dehumidification process will prevent the loss of sludge pressed into the filters in open installations being used nowadays with consequent drips and odors. The process of deactivation to the plant is reused in the recovery of reinforced concrete blocks, which, after appropriate chemical/physical analyses (sales test) and compression, traction and flaky tests will allow registration and the current re-use in various sectors (construction, embankments, environmental recovery, etc.).

The marketable products are not waste but secondary materials (mps) and therefore they are not regulated by the law on waste any longer (forms of identification, register of loading and unloading, losses, etc.).

The output data were monitored with the plant in operation from which we can verify that the expected objectives correspond to the substantial performance of the plant. Particurarly:

- the plant is able to accept at least 3 tons/hour of polluted sludge entering the process and produce at the exit of the process 6 cubic meters/hour of concrete made that is already vibrated and of high quality (equal to 7,5 tonne by weight).

- the conglomerate leaving the plant have structural quality characteristics with a resistance to compression of $180 \mathrm{~kg} / \mathrm{cm}^{2}$, using a quantity of cement less than $250 \mathrm{~kg}$ per cubic metre of concrete produced.

- $30 \%$ by weight of liquid components is extracted from the corresponding sludge to be treated separately from the dried waste.

- a reduction of $30 \%$ of the weight of the mud following dehydration and extraction of the organic part.

- a recovery of water not contaminated in measure of $15 \%$ in weight of the mud was obtained.

- a reduction of $30 \%$ of the precious raw materials as necessary for the inertization and treatment of the sludge was measured.

- the pollutant residue of the output product was complied with the limit concentration values as prescribed by the current legal rules on cement conglomerates and in particular with reference to the table in Annex 3 to D.M. 186/2006

- the production costs of the new plant is contained in a $+35 / 45 \%$ compared to the estimated production cost for a traditional plant for the production of concrete (concreting plant) assimilated to it for the traditional components of mixing, even if with lower production capacities. 
This new process, will be absolutely strategic to facilitate the transition towards a sustainable industry becoming a complementary phase of many industrial processes that by their nature produce waste downstream with a strong environmental impact neutralising the harmful effects of such waste and making it reusable.

The new process is strongly focused on recycling, cleaning, de-pollution and use of value-added materials from processing residues.

The project, in meaningful measure although not priority, also unites the ulterior technological fields:

Technologies related to a new generation of components and systems (advanced and intelligent integrated system and component engineering): to incorporate an "advanced integrated system" characterized by a sophisticated control logic that manages the proper functioning of all the constituent components of the new process.

Technologies for the plants of the future, capable of promoting productivity gains accompanied by a lower use of materials and energy, less pollution and less waste production: the new process by virtue of the new qualities and functionality, better described in this development plan, will guarantee:

- less use of materials: due to the fact of decreasing the amount of valuable materials (cement, mixed granulometric limestone, lime, various additives, etc...) necessary to demolish and process the same amount of waste/sludge by pre-treatment of incoming sludge drying.

- less pollution: avoids dispersion of volatile pollutants into the atmosphere by virtue of the closed cycle isolated from the atmosphere.

- less waste generation: it allows a wider use of industrial processing sludge/residues, transforming them into second raw materials (or products) to be returned to the market, avoiding that they are instead sent to landfill.

- improve the health and well-being of the population as it avoids the dispersion into the atmosphere of hydrocarbons and noxious volatile substances that could flow into the second raw material block and evaporate into the atmosphere and opens instead the possibility to separate and treat appropriately specific types of volatile pollutants conferring them in other specific plants.

- allowing the transition to a green economy through eco-innovation. The innovation that we want to make certainly has the requirements of eco-compatibility contributing to the reduction of pollutants dispersed in nature and making no contribution to pollution.

\section{CONCLUSIONS}

The present work presents a new method to retrain industrial sludge into construction products using a new Closed Cycle Drying Process. The research has shown that hazardous waste like also industrial muddy sludge can be recovered and reused in various sectors so to completely avoid landfills. In fact atmospheric air pollution is a growing problem and for this reason green technologies that include the industrial redevelopment of sludge and sustainable energy sources such as that generated by solar panels, wind turbines and biogas are becoming increasingly impotent [22]-[24].

The dehumidification treatment has indeed proposed waste after pulverization for easy handling and storage (silos) losing some of the characteristics that make moving and treating it difficult. It has permitted to reduce both management costs and the raw materials used in the deactivation process (cement, limestone, grains of different sizes, water).

A reduction of sludge volume of $1 / 3$ was possible, and in particular a quantity of odours that makes the sludge difficult to face was removed, without considering then the inhalation problems caused to workers assigned to the treatment.

\section{ACKNOWLEDGMENT}

This research was funded by Horizon 2020 and supported in part by a benefit obtained with the fund for the athenaeum research in Catania, research programme 2019/2021.

\section{REFERENCES}

[1] A. Mohajerani, A. Ukwatta, T. Jeffrey-Bailey, M. Swaney, M. Ahmed, G. Rodwell and S. Setunge, "A Proposal for Recycling the World's Unused Stockpiles of Treated Wastewater Sludge (Biosolids) in Fired-Clay Bricks.” Buildings, 9(1), 14. 2019

[2] H. X. Weng, X. W. Ma, F. X. Fu, J. J. Zhang, Z. Liu, L. X. Tianand C. Liu, "Transformation of heavy metal speciation during sludge drying: mechanistic insights." Journal of hazardous materials, 265, pp. 96-103. 2014.

[3] C. H. Weng, D. F. Lin and P. C. Chiang, "Utilization of sludge as brick materials." Advances in environmental research, 7(3), pp. 679685. 2003

[4] Directive, C. "Council directive on the protection of the environment, and in particular of the soil, when sewage sludge is used in agriculture.” Offic. J. Eur. Comm, 181, 0006-0012. 1986.

[5] C. Lue-Hing, Ed., Municipal sewage sludge management: A reference text on processing, utilization and disposal. CRC Press. 1998, vol. 4.

[6] F. D. Sanin, W. W. Clarkson, and P. A. Vesilind, "Sludge engineering: the treatment and disposal of wastewater sludges". DEStech Publications, Inc. 2011.

[7] G. Chen, P. Lock Yue, and A. S. Mujumdar, "Sludge dewatering and drying." Drying Technology, 20(4-5), pp. 883-916. 2002.

[8] B. F. C. Laurent, and J. Bridgwater, "Influence of agitator design on powder flow." Chemical Engineering Science, 57(18), 3781-3793. 2002 .

[9] W. Sutrisno, P. Suprobo, and E. Wahyuni, "Microstructural Investigation of Reinforced Concrete Exposed to Cyclic Wetting and Drying." International Journal on Advanced Science, Engineering and Information Technology, 8(2), pp. 411-417. 2018.

[10] N. Malekjani, S. M. Jafari, H. Mirzaee, and M. H. Rahmati, "Design and Application of a Novel Dehumidifying System for a Fluidized Bed Dryer for the Drying of Canola Seeds." International Journal on Advanced Science, Engineering and Information Technology, 1(1), pp. 46-49. 2011.

[11] F. Rapisarda, R. Zammataro, and G. Di Lorenzo, "Bio-Inspired Method for Advanced Industrial Sludge Treatment with Closed Cycle Drying Process." CEUR Workshop Proceedings, vol. 2145, pp. 139-146. 2018.

[12] L. Cocilovo, A. Fichera, and G. Di Lorenzo, "Geometric Modeling and Optimized Design of an Hydraulic System for Concrete Batching Plant." CEUR Workshop Proceedings, vol. 2152, pp. 37-43. 2018.

[13] G. C. Cardarilli, L. Di Nunzio, R. Fazzolari, D. Giardino, M. Matta, M. Re, and S. Spanò, "Efficient Ensemble Machine Learning Implementation on FPGA Using Partial Reconfiguration." International Conference on Applications in Electronics Pervading Industry, Environment and Society, pp. 253-259. Springer, Cham. 2018.

[14] P. S. V. Sathyanarayanan, "A Cloud Based Irrigation System for Agriculture." JOIV: International Journal on Informatics Visualization, 2(1), pp. 28-30. 2018. 
[15] M. Calì, S. M. Oliveri, R. Ambu, and G. Fichera, "An Integrated Approach to Characterize the Dynamic Behaviour of a Mechanical Chain Tensioner by Functional Tolerancing." Strojniski Vestnik Journal of Mechanical Engineering, 64(4), pp. 245-257. 2018.

[16] R. Ambu, "A method with a statistical approach for the evaluation of tolerance chains." Advanced Materials Research,vol. 651, pp. 601606, 2013.

[17] M. Calì, S. M. Oliveri, "Application of an effective SIMP method with filtering for topology optimization of motorcycle tubular frame." International Review of Mechanical Engineering, vol 11, Issue 11, pag. 836-844, Nov. 2017.

[18] R. Ambu, A. Manuello Bertetto, L. Mazza, "Re-design of a guide bearing for pneumatic actuators and life tests comparison." Tribology International 96, pp. 317-325. 2016.

[19] M. Calì, and F. Lo Savio, "Accurate 3d reconstruction of a rubber membrane inflated during a bulge test to evaluate anisotropy." Lecture Notes in Mechanical Engineering, 0, pp. 1221-1231, 2017.

[20] M. Calì, and R. Ambu, "Advanced 3D photogrammetric surface reconstruction of extensive objects by UAV camera image acquisition.” Sensors , vol. 18 (9), 2018
[21] M. Calì, S. M. Oliveri, U. Cella, M. Martorelli, A. Gloria, and D. Speranza, "Mechanical characterization and modeling of downwind sailcloth in fluid-structure interaction analysis." Ocean Engineering, 165, pp. 488-504. 2018

[22] G. Capizzi, G. Lo Sciuto, C. Napoli, and E. Tramontana, "A multithread nested neural network architecture to model surface plasmon polaritons propagation." Micromachines, 7(7), pp. 110. 2016.

[23] G. Capizzi, G. Lo Sciuto, P. Monforte, and C. Napoli, "Cascade feed forward neural network-based model for air pollutants evaluation of single monitoring stations in urban areas." International Journal of Electronics and Telecommunications, 61(4), pp. 327-332. 2015.

[24] G. C. Cardarilli, L. Di Nunzio, R. Fazzolari, D. Giardino, M. Matta, M. Re, and S. Spanò, "AQ-Learning based PSK Symbol Synchronizer." International Symposium on Signals, Circuits and Systems (ISSCS), pp. 1-4. IEEE. 2019. 